\title{
Mosquito Repellents: How much Relevant are they?
}

\section{Sumangala Bhat $\mathrm{K}^{*}$ and Aravind G}

Dextrose Technologies Pvt. Ltd., Bengaluru, India

*Corresponding Author: Sumangala Bhat K, Dextrose Technologies Pvt. Ltd., Bengaluru, Karnataka, India.
Received: October 19, 2021

Published: November 16, 2021

(C) All rights are reserved by Sumangala Bhat

$\mathrm{K}$ and Aravind Ganessin.

\section{Abstract}

Repellent technology is one of the oldest strategies used for mosquito control. These products have evolved and diversified over the years with value addition on user-friendly front and environmental safety aspects. An overview of the conventional and advanced strategies for mosquito control has been provided and the evolution of mosquito repellent formulations from synthetic chemical compounds to natural products and their application methods from simple coils to functionalized clothes have been discussed. While comparing the extent of relief provided by different control methods, repellents appear to be marginal. Despite this fact, mosquito repellents have carved a persistent and sustainable niche in mosquito control programs as an acceptable option over the centuries. The ready-to-use feature and handy application methods combined with effective formulations have driven the success of these products in the market. In the present context of the emergence of new mosquito-borne diseases and increased mobility of people across the world, mosquito repellents will remain practically relevant till the mosquito menace persists. Among the repellents, the importance and advantages of spatial repellent formations have been analyzed.

Keywords: Herbal; Eco-friendly; Sustainable Mosquito-borne Diseases; Spatial Repellents; Aedes

\section{Introduction}

Mosquitoes belong to a diverse family of insects, called Culicidae, having 3 subfamilies, namely Toxorhynchitinae, Anopheline, and Culicine. More than 3400 species of mosquitoes have been reported so far [1]. They are cosmopolitan in their distribution marking their presence from the tropical to the polar zones. However, they exhibit differential patterns of latitudinal distribution among various species, with the highest species diversity maintained in Southeast Asia and the Neotropics [2]. Meanwhile, a gradient in the diversity of mosquito species has been reported from the temperate to the tropical regions [3]. Mosquitoes enjoy a wide range of vertical distribution as well. The presence of mosquitoes has been reported from $6000 \mathrm{~m}$ above sea level on mountain ranges and $1250 \mathrm{~m}$ below sea level as in the case of mines and caves [4]. They are considered as highly invasive insects, expanding their territories to new areas continuously.
Mosquitoes are a group of high-risk household pests, with an established role as vectors for the transmission of human and animal diseases. Aedes aegypti and Ae. albopictus have been identified as the predominant species well adapted for successful invasion among the vector mosquitoes. The intimate association of these species with human dwellings, the endurance of their eggs to prolonged desiccation, and larval development in small and temporary water holdings in the vicinity of human habitation have contributed to their successful invasion and transmission of human pathogens [5]. The nature of severity, the types of diseases transmitted by mosquitoes, and the extent of disaster caused by them to public health have elevated them to the status of notorious vectors.

Encephalitis is a group of mosquito-borne diseases taking a heavy toll on human health and is transmitted by Culex spp. of mosquitoes. They also transmit many other viral infections among 
the human population across the world [6]. Many other viral infections like dengue, chikungunya, zika, etc. have attained the status of serious public health challenges with recurring incidences. Species of Aedes have been identified as the primary vectors of these pathogens [5]. The number of pathogens transmitted by mosquitoes, their cosmopolitan distribution [4], their invasive trend [5], and the physiological and behavioral resistance evolved by them to pest management strategies [7] make the process of mosquito control challenging.

The use of mosquito repellents is one of the strategies to manage mosquito menace and is in practice for a long time [8]. Mosquito repellents comprise a wide range of compounds of natural and synthetic origins [9]. Similar to other pest management products, synthetic compounds are more popular and in higher demand in the mosquito repellent product range and enjoy a large market share. DEET

(N, Ndiethyl- m-toluamide) represents the most popular and effective mosquito repellent [10]. Regardless of its extensive use as a repellent, this compound has also been reported to have environmental and health risks [11]. This has led to a focused attempt towards developing eco-friendly repellents from natural sources and new formulations of this range are in demand in the market.

This article intends to bring out the relevance of mosquito repellents as a large and powerful arsenal for mosquito control and the importance of environmentally safe alternatives to DEET and other synthetic chemicals in mosquito repellents.

\section{Mosquito control strategies}

Mosquito control is a worldwide health care strategy and is crucial in the prevention and management of mosquito-borne diseases. Mosquito control has got a long history and multiple strategies are evolved from time to time. Mosquito control strategies target different life stages of the mosquitoes, as well as aimed towards different outcomes via different approaches (Figure 1) [12-14]. The physiological and behavioral diversities of mosquito species demand specific strategies of control measures for individual species of mosquito. Conventional strategies are more popular and common approaches prevailing worldwide. However, few advanced methods have been evolved during recent years and have been tested on Ae. aegypti (Table 1). These techniques have further scope for improvement and customization against other vector mosquitoes.

\begin{tabular}{|c|c|c|c|}
\hline \begin{tabular}{|c|} 
Sl. \\
No. \\
\end{tabular} & Strategies & Description & Case studies \\
\hline 1 & $\begin{array}{c}\text { Advanced } \\
\text { Targeted } \\
\text { Sugar bait }\end{array}$ & $\begin{array}{c}\text { Attractive toxic sugar } \\
\text { bait (ATSB) coupled } \\
\text { with host kairomone } \\
\text { (L-lactic acid and } \\
\text { 1-octen-3-ol,) set up } \\
\text { at outdoor n sta- } \\
\text { tions. Both males and } \\
\text { females are attracted } \\
\text { in large numbers and } \\
\text { get trapped. }\end{array}$ & Florida, US [15] \\
\hline 2 & $\begin{array}{l}\text { Auto dis- } \\
\text { semination } \\
\text { augmented } \\
\text { by males } \\
\text { (ADAM) }\end{array}$ & $\begin{array}{c}\text { Larvicide, pyriproxy- } \\
\text { fen is dusted on males } \\
\text { which carry them to } \\
\text { larval habitats and } \\
\text { also disseminate to } \\
\text { females during mat- } \\
\text { ing. }\end{array}$ & $\begin{array}{l}\text { Tested on Ae. aegypti } \\
\text { Los Angeles, California, } \\
\text { Clovis, California, and } \\
\text { Key Largo, Florida and } \\
\text { found successful [16] }\end{array}$ \\
\hline 3 & $\begin{array}{l}\text { Incompat- } \\
\text { ible insect } \\
\text { technique } \\
\text { (Wolbachia } \\
\text { method) }\end{array}$ & $\begin{array}{c}\text { Infection of the } \\
\text { natural bacteria } \\
\text { Wolbachia to male } \\
\text { mosquitoes leads to } \\
\text { cytoplasmic incom- } \\
\text { patibility. Infected } \\
\text { male when mates } \\
\text { with uninfected } \\
\text { females, the eggs } \\
\text { produced by them } \\
\text { become unviable, } \\
\text { thereby sterilizing the } \\
\text { females. }\end{array}$ & $\begin{array}{l}\text { Applied on Ae. ae- } \\
\text { gypti [17] at Florida by } \\
\text { releasing more than } 6 \\
\text { million infected males } \\
\text { leading to more than } \\
70 \% \text { reduction in the } \\
\text { female population. }\end{array}$ \\
\hline 4 & $\begin{array}{l}\text { Trapping } \\
\text { egg laying } \\
\text { females }\end{array}$ & $\begin{array}{l}\text { Autodissemination } \\
\text { trap for mosquitoes }\end{array}$ & $\begin{array}{l}\text { In2Care trap (BV, Wa- } \\
\text { geningen, } \\
\text { The Netherlands). } \\
\text { Tested successfully in } \\
\text { the US. Gravid female } \\
\text { mosquito enters the } \\
\text { trap to lay eggs, where } \\
\text { pyriproxyfen or spores } \\
\text { of Beauveria bassiana } \\
\text { get stick on to the } \\
\text { mosquito body. Due to } \\
\text { the skip-oviposition } \\
\text { feature of Ae. aegypti, } \\
\text { the female carries the } \\
\text { pyriproxifen or the } \\
\text { fungal spores to other } \\
\text { oviposition sites. The } \\
\text { eggs laid in such areas } \\
\text { will get destroyed [18] }\end{array}$ \\
\hline
\end{tabular}

Table 1: Advanced Strategies for Mosquito Control. 


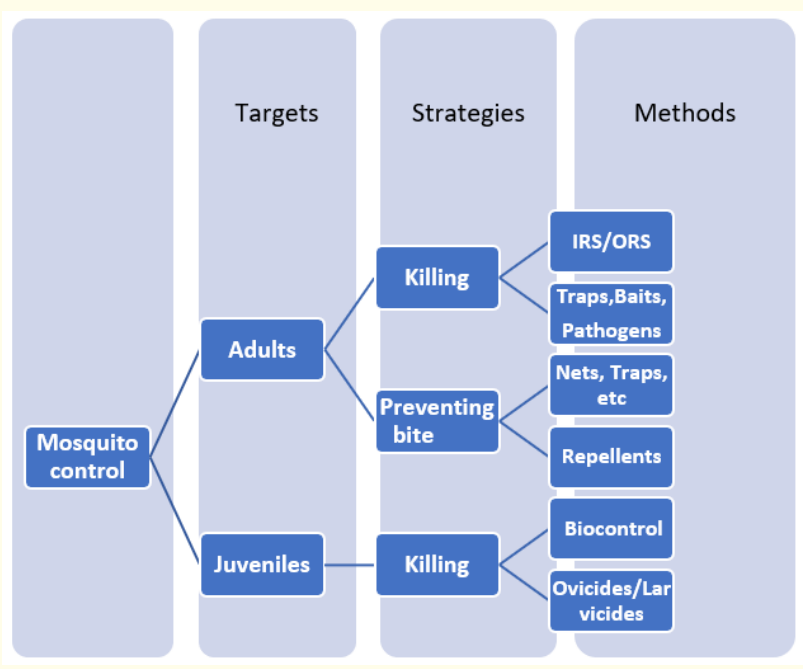

Figure 1: Conventional strategies for mosquito control.

IRS: Indoor Residual Spraying; ORS: Outdoor Residual Spraying.

\section{History and evolution of mosquito repellents}

Repellents are materials or formulations that deter arthropods from touching or biting a host or landing on a surface [19,20]. Generally, repellents create a barrier of vapor in the immediate surroundings of the protected surface [21]. Therefore, volatile compounds or materials containing them are often used in repellents. Plant essential oils have a long history as insect repellents. Citronella oil, Dialkyl Phthalates, Indalone, and Rutgers 612 [21] are few pioneering examples under this category. Commercial insect repellents have a long history that dates back to 1929 . The first repellent formulation of synthetic compounds, Indalone ${ }^{\circledR}$, got registered in 1937 [8]. This product enjoyed an extensive demand during the 1940s and 1950s.

DEET ( $\mathrm{N}, \mathrm{N}$ diethyl- m-toluamide), is a magic compound introduced to mosquito repellent formulations during 1956 and enjoys the status as the most popular active ingredient in commercial synthetic repellents against vector mosquitoes [10,22], despite the environmental and health concerns associated with this compound $[11,23]$ even today. A synthetic pyrethroid, Permethrin, another synthetic compound of the pyrethroid group was introduced to the market in 1973 as an alternative to DEET [22]. This is extensively used in preparing mosquito repellent nets, particularly for the management of malaria in the United States [24,25]. Picaridin [2-(2-hydroxyethyl)-1-piperidine carboxylic acid 1-methyl propyl ester] is yet another compound introduced in different parts of the world for mosquito control during 1998 [26] with the endorsement of the WHO [27]. In India, the DRDO has confirmed the insect repellent property of $\mathrm{N}$, n- dialkyl -morpholin- 4 - carboxamide compounds and developed a process for their synthesis [28].

A phenomenal surge in public concern regarding the environmental and health risks associated with mosquito repellents has driven the scientific community towards a search for environmentally sustainable and safe repellents against mosquitoes. The use of phytochemicals and essential oils of plants as mosquito repellents has gained momentum and formulations developed from volatile compounds and essential oils have been evolved and put into use against blood-sucking arthropods [29]. Mosquito repellent activity of citronella oil is well-known since the 1940s and is still used for this purpose, despite its efficacy being inferior in comparison with synthetic compounds [21]. Similarly, several studies have confirmed the mosquito repellent activities of extracts and oils of Lantana camara, Artemisia vulgaris, Vitex negundo, lemongrass, eucalyptus, etc. [30-32].

Mosquitoes are highly diversified and evolved parallel to human beings. The behavioral resistance developed by the vector mosquitoes towards insecticides is very complex with huge knowledge gaps. This poses formidable challenges in evolving successful mosquito control strategies. Repellents represent one of the oldest strategies employed for vector control. Mosquito repellents have evolved in terms of the active ingredients, formulations, and modes of application. Accordingly, mosquito repellent formulations have diverse groups of active components. Synthetic chemicals have been replaced with natural products like oils and extracts of plant materials. Amines and pyridines represent major groups of insect repellents of plant origin [33]. The synergistic activities of the metabolites present in the essential oils have been found to bring higher levels of bioactivity compared to the activities of isolated components $[34,35]$. A combination of active components and additives has been used as a strategy for improving the efficacy and shelf-life of repellents. Many additives such as salicylic acid, liquid paraffin [36,37], mustard oil, and coconut oil [38] are used to enhance the efficacy of the essential oils against mosquitoes. Vanillin is a popular additive used in mosquito repellent formulations $[20,37,39]$. Sustained release of the active components is another 
latest trend in the application of mosquito repellents. Chitosan encapsulated citronella oil microcapsules have been on trial [40]. Natural repellents are preferred over chemical repellents [41]. Plant-derived repellents are safe and reliable prevention options against mosquitoes [37] and have been approved as safe by the FDA [42]. Natural mosquito repellents have great market potential in terms of both diversity and volume demand [43]. In addition to the repellent ingredients, the mode of application of the formulations also has evolved during recent years. Incorporation of mosquito repellents into textiles, mosquito nets, wearable patches, bands, etc. $[12,43]$ have added to the user-friendly index of the products and brought a better level of consumer acceptance. While analyzing the relevance, potential, and prospects of mosquito repellents in general, Norris and Coats have opined spatial repellent formulations of botanical origin would lead the whole race due to their multiple advantages over other types of repellent compositions and application modes. The botanical-derived spatial repellents, have heterogeneous compositions and are hence capable of targeting multiple species of vector mosquitoes, better endurance against resistance development by mosquitoes, and long-lasting activity. Since the spatial repellents are not applied to the human body, they are safer for the users than topical applicants or wearable devices [44].

Despite having a long history, the plant-derived essential oils as mosquito repellents, efforts to develop them into commercial formulations from them remained as a low-key affair until the late 1990s. Considering the environmental sustainability and public acceptance of the botanical extracts, essential oils, and other derivatives, the potential of these agents for mosquito control is highly relevant. In addition to this, the advantages of the spatial repellent formulations need to be capitalized by making value addition to such formulations through enabling smart application modes and other means.

\section{Effects of mosquito repellents on users}

The safety of insect repellents including mosquito repellents is a cause of concern. A report of the Citizens Environmental Research Institute [45] has reported multiple acute and chronic adverse effects among users of mosquito repellents in New York. The most common acute side effects reported by a community survey from Delhi, India have reported several acute adverse effects like headache, sore throat, cough, eye irritation, and allergy [46]. The frequencies and intensities of such side effects vary across different places, types of repellents and demographic and socioeconomic status of the populations analyzed $[45,46]$. One of the recent advanced investigations based on case studies of adverse effects of mosquito repellents from India has reported the long-term toxic effects on body systems leading to disruptions of biochemical pathways and production intermediate metabolites, biotransformation, and bioaccumulation due to overexposure to these products [47]. It is to be noted here that all these studies have been carried out on chemical mosquito repellent products. Herbal or botanical products have been recommended as safe and effective alternatives for these harmful chemicals $[43,44]$.

\section{Conclusion}

Mosquito repellents provide a temporary solution for minimizing mosquito bites. Despite being an ad-hoc solution to prevent mosquito bites, this strategy and products have thrived for centuries, as they account for a large share of the mosquito control market even today. Therefore, mosquito repellents have retained a unique and sustainable status among mosquito control strategies and product range over the centuries. The instant application at all emergency situations as a personal safety option, say during travel, transit stay, for use at remote places, etc. make them ever in demand, in comparison with many other long-term, effective, and advanced solutions for mosquito regulation. Mosquito repellents can be a personal belonging to everyone anywhere and everywhere and at any time. Therefore, there is a need for the development and commercialization of these products continuously. Eco-friendly formulations which can be used by all age groups and longer periods of efficacy need to be developed and promoted. These products will offer a safer choice for mosquito management. Meanwhile, the scientific community and the healthcare system should be vigilant about any adverse effects of these products.

\section{Bibliography}

1. Reiter P. "Climate change and mosquito-borne disease". Environmental Health Perspectives 109.1 (2001): 141-161.

2. Gaston $\mathrm{KJ}$ and Hudson E. "Regional patterns of diversity and estimates of global insect species richness". Biodiversity and Conservation 3 (1994): 493-500.

3. Foley Desmond H., et al. "Insight into global mosquito biogeography from country species records". Journal of Medical Entomology 44.4 (2007): 554-567. 
4. Lane RP and Crosskey RW. "Medical Insects and Arachnids". British Museum Edition. Chapman and Hall, London, UK 50 (1993).

5. Manguin Sylvie and Christophe Boëte. "Global Impact of Mosquito Biodiversity, Human Vector-Borne Diseases and Environmental Change". in: A. Lopez - Pujol (Edition.) The Importance of Biological Interactions in the Study of Biodiversity (2011): 27-50.

6. Information on http://www.who.int/water_sanitation_ health/resources/vector007to28.pdf. Accessed: 2/10/2016

7. Sokhna Cheikh M., et al. "The changes in mosquito vector behavior and the emerging resistance to insecticides will challenge the decline of malaria". Clinical Microbiology and Infection 19.10 (2013): 902-907.

8. Peterson Chris and Joel Coats. "Insect repellents-past, present and future". Pesticide Outlook 12.4 (2001): 154-158.

9. Dethier VG. "Repellents". Annual Review of Entomology 1.1 (1956): 181-202.

10. Isman Murray B. "Botanical insecticides, deterrents, and repellents in modern agriculture and an increasingly regulated world". Annual Review of Entomology 51 (2006): 45-66.

11. Pitasawat B., et al. "Repellency of aromatic turmeric Curcuma aromatica under laboratory and field conditions". Journal of Vector Ecology: Journal of The Society for Vector Ecology 28.2 (2003): 234-240.

12. Patra Aparajita., et al. "Current developments in (Malaria) mosquito protective methods: a review paper". International Journal of Mosquito Research 6.1 (2019): 38-45.

13. Jones RT., et al. "Novel control strategies for mosquito-borne diseases". Philosophical Transactions of the Royal Society $B$ (2021): 20190802.

14. McGregor BL and Connelly CR. "A review of the control of Aedes aegypti (Diptera: Culicidae) in the continental United States". Journal of Medical Entomology 58.1 (2021): 10-25. toxic sugar baits for surveillance and control of Aedes aegypti and Aedes albopictus in Florida". Parasites and Vectors 10.1 (2017): 1-9.

16. Brelsfoard CL., et al. "Aedes aegypti males as vehicles for insecticide delivery". Insects 10.8 (2019): 230.

17. Mains JW., et al. "Localized control of Aedes aegypti (Diptera: Culicidae) in Miami, FL, via inundative releases of Wolbachiainfected male mosquitoes". Journal of Medical Entomology 56.5 (2019): 1296-1303.

18. Snetselaar J., et al. "Development and evaluation of a novel contamination device that targets multiple life-stages of Aedes aegypti". Parasites and Vectors 7.1 (2014): 1-10.

19. Blackwell AE., et al. "The repellent and anti-feedant activity of oil of Myrica gale against Aedes aegypti mosquitoes and its enhancement by the addition of salicyluric acid". The Journal of the Royal College of Physicians of Edinburgh Edinburgh 33 (2003): 209-214.

20. Choochote W., et al. "Repellent activity of selected essential oils against Aedes aegypti”. Fitoterapia 78.5 (2007): 359-364.

21. Brown Margaret and Adelaide A Hebert. "Insect repellents: an overview". Journal of the American Academy of Dermatology 36.2 (1997): 243-249.

22. Katz Tracy M., et al. "Insect repellents: historical perspectives and new developments". Journal of the American Academy of Dermatology 58.5 (2008): 865-871.

23. Fradin MS. "Insect repellents", in S.E. Wolverton (Edition.), Comprehensive dermatologic drug therapy, Saunders Elsevier, Indianapolis (2007): 785-801.

24. Kimani EW., et al. "Use of insecticide-treated clothes for personal protection against malaria: a community trial". Malaria Journal 5.1 (2006): 1-9.

25. Schreck CE., et al. "Activity of repellents applied to skin for protection against Amblyomma americanum and Ixodes scapularis ticks (Acari: Ixodidae)". American Mosquito Control As-

15. Scott-Fiorenzano JM., et al. "Evaluations of dual attractant

Citation: Sumangala Bhat K and Aravind G. "Mosquito Repellents: How much Relevant are they?". Acta Scientific Medical Sciences 5.12 (2021): $68-73$. 
sociation 11.1 (1995): 136-140.

26. Abramowitz M. "Picaridin a new insect repellent". Medical Letter 47 (2005): 46-47.

27. Information J.

28. Ambati NR., et al. "N, N- dialkyl -morpholin- 4 - carboxamide compounds as insect repelling agents and a process for their preparation". India, WO Patent App (2012).

29. Curtis CF., et al. "Natural and synthetic repellents". in: C.F. Curtis (Edition.), Appropriate Technology in Vector Control, CRC Press, Florida, Chapter 4 (1990).

30. Hebbalkar DS., et al. "Mosquito repellent activity of oils from Vitex negundo Linn. leaves". The Indian Journal of Medical Research 95 (1992): 200-203.

31. Dua VK., et al. "Repellency of Lantana camara (Verbenaceae) flowers against Aedes mosquitoes". Journal of the American Mosquito Control Association 12.3-1 (1996): 406-408.

32. Vivek Kempraj and Bhat sK. "Ovicidal and larvicidal activities of Cyperus giganteus Vahl and Cyperus rotundus Linn. essential oils against Aedes albopictus (Skuse)". Natural Product Radiance 7.5 (2008): 420-425.

33. Varma Jaya and Dubey NK. "Prospectives of botanical and microbial products as pesticides of tomorrow". Current Science (1999): 172-179.

34. Hummel Brunner., et al. "Acute, sub lethal, anti feedant, and synergistic effects of monoterpenoid essential oil compounds on the tobacco cutworm, Spodoptera litura (Lep., Noctuidae)". Journal of Agricultural and Food Chemistry 49.2 (2001): 715720.

35. Gillij YG., et al. "Mosquito repellent activity of essential oils of aromatic plants growing in Argentina". Bioresource Technology 99.7 (2008): 2507-2515.

36. Oyedele AO., et al. "Formulation of an effective mosquito-repellent topical product from lemongrass oil". Phytomedicine 9.3 (2002): 259-262.

37. Tawatsin A., et al. "Repellency of volatile oils from plants against three mosquito vectors". Journal of Vector Ecology 26 (2001): 76-82.

38. Das NG., et al. "Field evaluation of herbal mosquito repellents". The Journal of Communicable Diseases 31.4 (1999): 241-245.

39. Khan AA., et al. "Addition of vanillin to mosquito repellents to increase protection time". Mosquito News 35 (1975): 223-225.

40. Hsieh Wen-Chuan., et al. "Controlled release properties of chitosan encapsulated volatile citronella oil microcapsules by thermal treatments". Colloids and Surfaces B: Bio Interfaces 53.2 (2006): 209-214.

41. Shukla D., et al. "Effective mosquito repellent from plant-based formulation". International Journal of Mosquito Research 5.1 (2018): 19-24.

42. Trongtokit Y., et al. "Comparative repellency of 38 essential oils against mosquito bites". Phytotherapy Research 19.4 (2005): 303-309.

43. Bhat S K and Aravind G. "Evolution, Current Status and Prospects of Phyto-Repellents against Mosquitoes". International Journal of Pharmacology Phytochemistry and Ethnomedicine 8 (2017): 54-73.

44. Norris Edmund J and Joel R Coats. "Current and Future Repellent Technologies: The Potential of Spatial Repellents and Their Place in Mosquito-Borne Disease Control". International Journal of Environmental Research and Public Health 14.2 (2017): 124-129.

45. Abby Stahl. "The Health Effects of Pesticides Used for Mosquito Control". in: Sarah J. Meyland and Adrienne Esposito (Edition.). A Report By: Citizens Campaign for The Environment and Citizens Environmental Research Institute (2002).

46. Kohli C., et al. "Usage and Perceived Side Effects of Personal Protective Measures against Mosquitoes among Current Users in Delhi". Journal of Parasitology Research 2014 (2014): 628090 .

Volume 5 Issue 12 December 2021 (C) All rights are reserved by Sumangala Bhat $\mathrm{K}$ and Aravind G. 